\title{
Artigos
}

\section{Acidentes de trabalho e atuação do Centro de Referência em Saúde do Trabalhador nas páginas do Jornal de Piracicaba entre 2007 e 2014}

\author{
Occupational accidents and the performance of the Occupational Health \\ Reference Center in the pages of the Jornal de Piracicaba newspaper \\ between 2007 and 2014 (abstract: p. 16)
}

\section{Accidentes de trabajo y actuación del Centro de Referencia en Salud del Trabajador en las páginas del periódico Jornal de Piracicaba, entre 2007 y 2014 (resumen: p. 16)}

José Marçal Jackson Filho(a)

<jose.jackson@fundacentro.gov.br>

Eduardo Garcia Garcia ${ }^{(\mathrm{b})}$

<edgarcia@fundacentro.gov.br> (iD)

Honasses Guardiola David(c)

<honasses.david@joinville.sc.gov.br>

Sandra Renata Canale Duracenko(d)

<cerest@piracicaba.sp.gov.br> iD

Angela Paula Simonelli(e)

<angelasimonelli@ufpr.br>

\author{
(a) Centro Estadual do Paraná, Fundação \\ Jorge Duprat Figueiredo de \\ Medicina e Segurança do Trabalho \\ (Fundacentro). Rua Paula Gomes, \\ 313, São Francisco. Curitiba, PR, \\ Brasil. 80510-070. \\ (b) Coordenação de Saúde do \\ Trabalhador, Centro Técnico \\ Nacional, Fundacentro. São Paulo, \\ SP, Brasil. \\ (c) Secretaria Municipal de Saúde de \\ Joinville. Joinville, SC, Brasil. \\ (d) Centro de Referência em Saúde do \\ Trabalhador, Secretaria Municipal de \\ Saúde. Piracicaba, SP, Brasil. \\ (e) Departamento de Terapia \\ Ocupacional, Setor de Ciências da \\ Saúde, Universidade Federal do \\ Paraná. Curitiba, PR, Brasil.
}

A prevenção de acidentes de trabalho não é tema frequente na mídia impressa. A atuação do Centro de Referência em Saúde do Trabalhador de Piracicaba, estado de São Paulo, Brasil (Cerest) coloca essa problemática no centro do debate social na região. 0 objetivo desta pesquisa foi identificar e descrever os temas e ações do Centro que suscitaram o interesse do Jornal de Piracicaba, o principal do município, e a visão que propaga sobre o serviço e sobre o tema. Foram analisados, sob duas categorias, 146 textos publicados entre 2007 e 2014, contendo como temas "problemática dos acidentes de trabalho" e "ações de vigilância". Verificou-se que o jornal dá voz aos atores sociais envolvidos e fundamenta sua cobertura com informações e ações desenvolvidas pelo serviço, colaborando, assim, na legitimação da política pública conduzida pelo Centro e evidenciando o papel da mídia local para resolução de problemas sociais que envolvem a comunidade.

Palavras-chave: Jornalismo. Saúde do trabalhador. Política pública. Vigilância. Acidente do trabalho. 


\section{Introdução}

A mídia cumpre papel importante no acompanhamento das políticas públicas, expondo-as ao grande público; e influenciando sua continuidade e condução ${ }^{1}$. Ao escolher temas, a mídia dirige o olhar do público para determinadas questões, ações e atores.

Não é ator neutro, imparcial, que retrata a realidade objetivamente. A produção jornalística depende de certos critérios de noticiabilidade ${ }^{2}$, isto é, dos valores inerentes aos eventos que motivam sua publicação e da relação dos jornalistas com representantes da economia ou da política, o que explica a saliência de determinados temas, a forma com que são enquadrados ${ }^{2-5}$ e o papel da mídia regional para tratar de temas de interesse local ${ }^{6}$.

Assim, políticas e serviços públicos de cunho social, como é o caso do Sistema Único de Saúde (SUS), tendem a não ter destaque ou a receber olhar crítico por parte dos jornais ou televisão?.

As relações que a mídia e o SUS entretêm são, todavia, diversas e complexas, o que justifica o interesse em analisá-las ${ }^{8}$. Por um lado, a mídia pode ter papel importante para a promoção da saúde ${ }^{8,9}$. Por outro, estudos mostram que a visão reducionista sobre os agravos de saúde, que atribui a causa aos indivíduos e ao seu comportamento, pouco contribui para a promoção da saúde, sendo comum nos meios de comunicação $0^{10,11}$.

No campo da saúde e do trabalho, o mesmo pode ser dito sobre a reação da mídia no caso dos acidentes do trabalho ${ }^{12}$, explicando-os, em geral, como resultantes de comportamentos inseguros, visão redutor $\mathrm{a}^{13} \mathrm{e}$ predominante no meio profissional e institucional, que, além de ineficiente para a prevenção, serve para culpabilizar as vítimas e proteger as empresas e instituiçôes.

Ações de comunicação junto à mídia são preconizadas para o campo da Saúde do Trabalhador ${ }^{14}$ para pautar a questão dos acidentes de trabalho, difundir visão mais abrangente sobre seu enfrentamento e as açóes dos serviços.

Nesse sentido, a presença importante do Cerest de Piracicaba na mídia impressa local ${ }^{15}$ merece ser compreendida, pois sua atuação na prevenção de acidentes coloca essa problemática no debate social no município e região ${ }^{16}$. O olhar da mídia sobre a atuação de serviços de saúde do trabalhador é tema pouco presente, por enquanto, na literatura científica.

\section{Desenvolvimentos do Cerest de Piracicaba}

Desde 1997, o Cerest (na época denominado Programa de Saúde do Trabalhador) realiza ações de vigilância aos acidentes de trabalho em Piracicaba e, a partir de 2003 (já credenciado como centro de referência), nos 14 demais municípios que estão sob sua jurisdição. As práticas de vigilância no serviço sempre tiveram como base os preceitos enunciados na Portaria 3908/98, "que aprova a instrução normativa de Vigilância em Saúde do Trabalhador no SUS"17.

Visando a uma perspectiva ampla de vigilância, o Cerest atua de forma articulada com outras instituiçôes - Ministério do Trabalho e Emprego (MTE) e Ministério Público do Trabalho (MPT) - e sindicatos para aumentar seu poder de agir no âmbito da prevenção de acidentes ${ }^{16,18}$. Foram realizados acordos em setores de alta acidentabilidade, originados em geral por acidentes graves ${ }^{16,18}$. 
O Sistema de Vigilância de Acidentes do Trabalho (Sivat), desenvolvido em parceria com a academia e implementado em 2003, é ferramenta essencial para as ações de vigilância, pois contém um banco de dados dos registros de acidentes oriundos de todos os hospitais do município. Dessa forma, permite a definição de ações prioritárias a partir dos indicadores de acidentabilidade (mortes, frequência e setores da economia), assim como orienta a investigação de acidentes graves, fatais e de menores de 18 anos $^{18}$.

A formação em Ergonomia, ofertada em meados dos anos 2000 como ação de capacitação para seus profissionais, subsidiou o desenvolvimento de ações de assistência, de reabilitação e de vigilância ${ }^{13}$. Foram realizadas açóes ergonômicas na indústria de abate, fabricação de móveis, têxtil e de alimentos.

Além disso, o Cerest realiza diversas açóes de promoção, entre elas, o Fórum de Acidentes do Trabalho, que desde 2008 serve de arena para promover nova perspectiva, sistêmica, para explicar e agir sobre os acidentes do trabalho ${ }^{18}$.

Se esse amplo esforço no campo da prevenção de acidentes é reconhecido, tanto institucionalmente quanto no meio acadêmico ${ }^{16}$, a mídia pode contribuir para maior visibilidade do serviço. É preciso também agir sobre a mídia para que adote visão mais abrangente sobre os fenômenos da Saúde dos Trabalhadores, favorecendo as ações do serviço ${ }^{14}$.

Em pesquisa descritiva, foi destacada a presença importante do Cerest na mídia impressa de Piracicaba entre 2007 e 2012, a partir de material de 3 jornais locais. Nela, as matérias publicadas por um deles - o Jornal de Piracicaba (JP) - representaram mais da metade da totalidade das notícias que compuseram o corpus analisado ${ }^{15}$.

Diante disso, o objetivo desta pesquisa é duplo: 1) analisar a cobertura da atuação do Cerest pelo JP no período compreendido entre 2007 e 2014; e 2) analisar a cobertura sobre a temática dos acidentes de trabalho e qual foi a contribuição do serviço.

\section{Métodos}

O material de análise é composto por textos publicados no JP no período de 2007 a 2014.

O JP é o mais tradicional da cidade e um dos mais importantes jornais do interior de São Paulo, sendo fundado em agosto de 1900, com publicação ininterrupta e tiragem de mais de 22 mil exemplares por $\mathrm{dia}^{15,19}$.

Piracicaba é um município com mais 364.571 mil habitantes em 2010 (estimativa de mais de 400 mil em 2018), com $1.378 \mathrm{~km}^{2}$ de área, localizado no interior de São Paulo, a $152 \mathrm{~km}$ da capital ${ }^{20}$. Possui importante papel na produção no setor sucroalcooleiro e parque industrial diversificado: indústria metalúrgica, produção de móveis, fabricação de equipamentos industriais, montagem de veículos leves e tratores, indústrias química e alimentícia, entre outras.

\section{Referencial para analisar a cobertura do JP}

Para analisar a cobertura jornalística da atuação do serviço e da temática dos acidentes, adotou-se a perspectiva proposta por Porto ${ }^{21}$ para estudar as relaçóes entre mídia e política, baseada na noção de enquadramento. 
Segundo Porto, enquadrar é um recurso usado nos meios de comunicação para construir interpretações dos fatos e problemas a partir de processos de seleção, ênfase e saliência, que permitem seu entendimento, avaliação e resolução ${ }^{21}$.

Os enquadramentos da mídia podem ser categorizados em noticiosos e temáticos ${ }^{21}$. Na primeira categoria, trata-se de "padrões de apresentação, seleção e ênfase utilizados pelos jornalistas para organizar seus relatos” (p. 91). Valem-se, de modo geral, de narrativas, cujo modo de comunicação "pressupóe uma estratégia textual que interfere na organização do discurso e que o estrutura na forma de sequências encadeadas. Pressupóe uma retórica que realiza uma finalidade desejada” (p. 2-3).

$\mathrm{Na}$ segunda, são "padrões de interpretação que promovem uma avaliação particular de temas e/ou eventos políticos, incluindo definiçôes de problemas, avaliaçóes sobre causas e responsabilidades, recomendaçôes de tratamento, etc.” (p. 92). Nos últimos, os jornalistas se valem das interpretaçóes e posiçôes dos atores sociais envolvidos nas questôes tratadas ${ }^{21}$.

Por meio da análise do conteúdo discursivo, é possível ter acesso às "perspectivas específicas de interpretação da realidade” (p. 193), pois "é no conteúdo que se busca o quadro, visto com espécie de ângulo, que permite compreender uma interpretação proposta em detrimento de outras.” (p. 194) 22.

\section{Procedimentos}

Os textos analisados fazem parte da base de dados criada e arquivada no próprio Cerest, por uma funcionária que os selecionava e coletava aqueles associados às açôes do serviço e de seus profissionais; e aos eventos que a instituição participava, além dos que citavam parceiros institucionais do serviço e aqueles cujo tema envolvia acidentes e doenças ocupacionais. Foram incluídos todos os textos que continham a palavra "Cerest", excluindo cartas, totalizando 146 matérias. Decidiu-se pelo período entre 2007 e 2014 pelo fato de o respectivo acervo se encontrar completo.

Os textos - notícias, manchetes de primeira página, editoriais e artigos de opinião - foram lidos por dois pesquisadores e classificados segundo o tema principal. Identificaram-se os atores envolvidos, as entrevistas concedidas por membros do serviço, a presença da palavra "Cerest" nos títulos ou subtítulos das matérias, o uso de dados do Sivat e os comentários sobre o serviço.

Em seguida, os textos foram categorizados em: problemática dos acidentes de trabalho; ações de vigilância; ações de promoção da saúde; Cerest; sindicatos e outros atores institucionais.

No que tange ao tratamento dos dados, procedeu-se, inicialmente, à análise descritiva e quantitativa dos textos, para, em seguida, realizar análise do conteúdo (qualitativa) do material das duas primeiras categorias, que contêm maior número de textos e permitem compreender como o JP enquadra a questão dos acidentes e a atuação do Cerest.

Todos os artigos foram considerados. Dessa forma, visou-se menor profundidade na análise, mas abarcou-se toda a extensão da cobertura jornalística.

Para tratar da temática de acidentes, buscou-se analisar o tema principal e sua caracterização, subtemas, os atores sociais chamados a se posicionar - em especial pertencentes ao Cerest - as interpretaçóes contraditórias e, se possível, a posição do JP. 
As coberturas das ações de vigilância foram inicialmente separadas em dois grupos: ações de vigilância "ordinárias” e investigações de acidentes. Em seguida, agruparam-se por setores da economia. A análise dos textos visava extrair os objetos centrais das açóes, os atores envolvidos, a posição referida pelos técnicos do Cerest e medidas tomadas. Enfim, se emitida, a posição do JP era evidenciada.

\section{Resultados}

Sobre a presença do Cerest nas páginas do JP entre 2007 e 2014, foram publicados 146 textos contendo a palavra "Cerest", distribuídos em notícias (140), editoriais (4) e artigos de opinião (2), sendo que 13 foram manchetes.

\section{Textos}

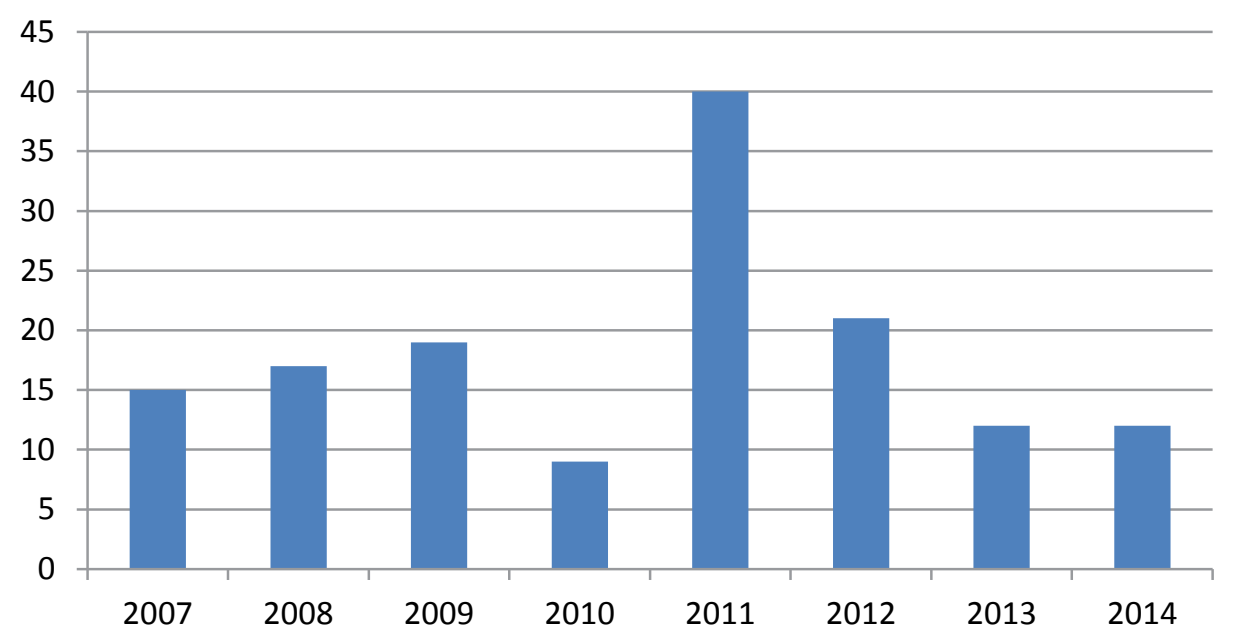

Figura 1. Quantidade de textos mencionando "Cerest" publicados no JP no período de 2007 a 2014

Pode-se notar na figura 1 que apenas em 2010 o JP publicou menos de dez textos. Em 2011, observa-se grande número de textos (quarenta), muito acima da média por ano, que é de aproximadamente 18 textos por ano nesse período.

Diversos textos contêm informaçóes fornecidas pelo Cerest, seja por meio do seu banco de dados, seja por meio de entrevistas com seus profissionais. Dos 146 textos, em 71 deles, pelo menos um profissional do Cerest foi entrevistado e, em 37 deles, dados extraídos do Sivat foram referidos.

Setores da economia são mencionados em 97 textos, sendo os mais presentes construção civil (61), indústria de transformação (13) e agricultura (8). Embora distribuídos ao longo dos oito anos (exceto 2010), houve grande concentração de textos no setor da construção em 2011. 
Temas publicados: a intervenção do Cerest na prevenção de acidentes segundo o JP

O Cerest está associado ou foi referenciado em matérias categorizadas em seis temas segundo seu objeto principal (figura 2): problemática dos acidentes de trabalho (AT 27), ações de vigilância (80), ações de promoção da saúde (16), o próprio Cerest (10), sindicatos (6) e outros atores (6).

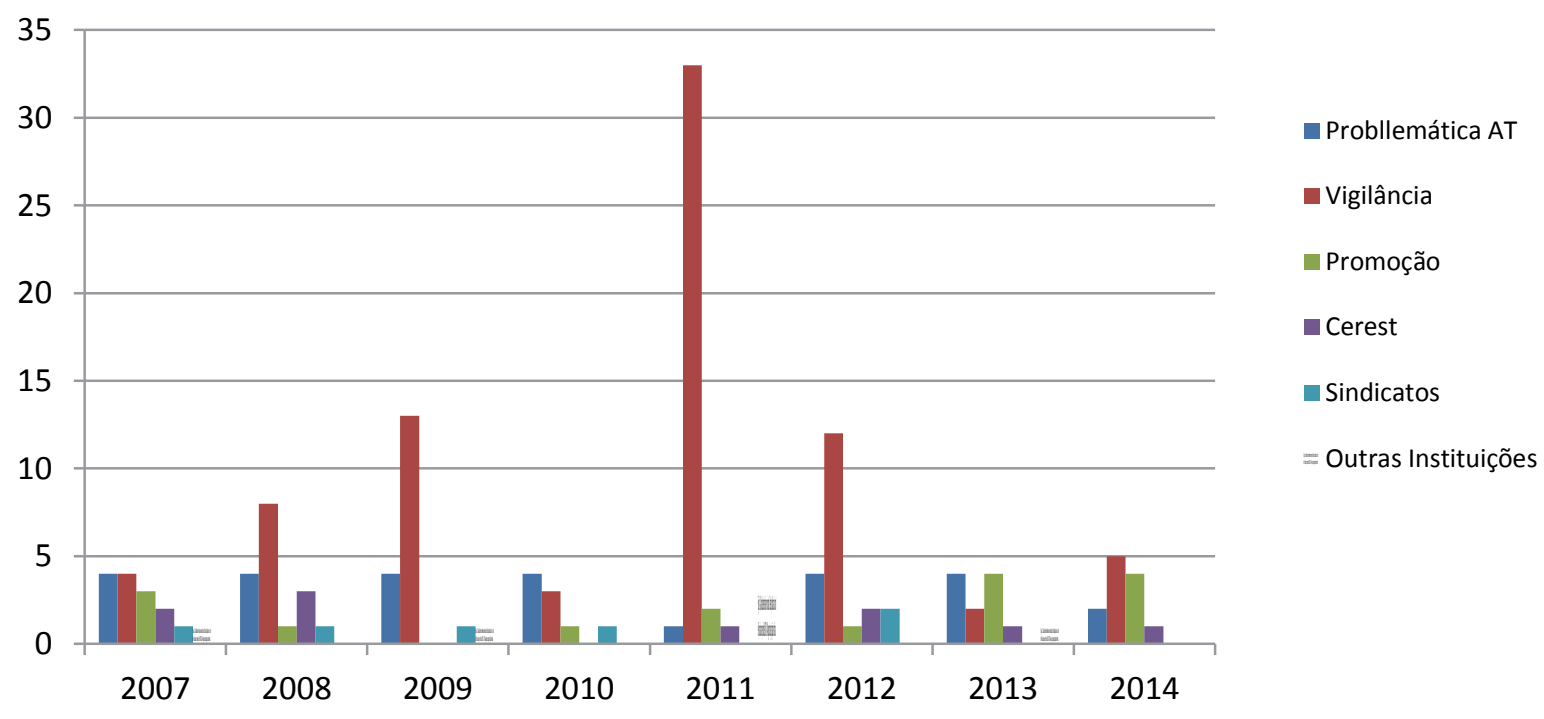

Figura 2. Quantidade de textos mencionando Cerest publicados no JP no período de 2007 a 2014 segundo categorização temática

\section{A problemática dos acidentes do trabalho nas páginas do JP: a contribuição do Cerest}

Entre 2007 e 2014, o JP publicou 24 notícias e três editorias sobre a problemática dos acidentes de trabalho. Dedicou de um a três textos por ano focando as estatísticas dos acidentes de trabalho na cidade, abordando tendências e explicaçóes para seu aumento e diminuição (13 textos, exceto nos anos de 2013 e 2014) - por vezes focando o caso específico do setor da construção civil (cinco notícias) -, além de temas diversos (seis notícias).

No início de cada ano, entre 2007 e 2012, uma reportagem cobria o que havia ocorrido no ano anterior - como número de acidentes segundo gravidade, mortes, setores com maior prevalência e explicaçóes para a tendência comparada ao período anterior - sendo que, em quatro dos seis anos, o tema foi publicado como manchete de primeira página. Além disso, o jornal acompanhava a evolução periódica dos acidentes com mais uma ou duas notícias por ano (exceto 2011).

Dessa forma, pode-se notar a tendência de crescimento do número de acidentes no município: 6653 em 2006 (01/05/2007), 8225 em 2007 (22/01/2008) e 11100 em 2008 (09/01/2009). A série crescente foi interrompida pela crise que levou à diminuição de ocorrências, 8987 em 2009 (07/03/2010) e posterior retomada da 
tendência de crescimento, com 9675 em 2010 (13/04/2011) e 10111 em 2011 (14/01/2012). Quanto ao número de mortes, a influência da crise não foi tão importante: sete casos em 2006, dez em 2007, 13 em 2008, 12 em 2009, 15 em 2010 e 13 em 2011. Os setores da metalurgia e alimentação eram responsáveis pelo maior número de acidentes; a construção civil apresentava, em geral, número importante de mortes $(03 / 10 / 2012)$.

Os dados apresentados pelo jornal haviam sido fornecidos pelo Cerest, extraídos do Sivat. A partir dessa base concreta, o JP trazia ao público a opinião de membros do Cerest, sindicalistas e representantes do patronato para explicar o fenômeno, cuja tônica se fundava em pontos de vista diversos, complementares ou opostos.

O jornal "dava voz" aos membros do serviço que se posicionavam diante das tendências observadas (aumento, queda do número de acidentes, setores mais críticos, entre outras) defendendo um ponto de vista para explicar o fenômeno, não compartilhado, via de regra, pelos representantes patronais.

Para explicar o aumento do número de acidentes em 2007, o então coordenador do serviço afirmou: "uma das hipóteses é o ritmo de trabalho para atender as demandas do crescimento econômico e gerar lucro" (22/01/2008); hipótese considerada sem sentido para o presidente do sindicato patronal da indústria, que alegou: "para a empresa, é um prejuízo ter funcionário acidentado. Alguns casos são por inexperiência”. Em matéria de 2009, segundo o técnico do serviço, o aumento do número de acidentes em 2008 também foi consequência do crescimento da economia e, portanto, da produção e do ingresso de mais trabalhadores. $O$ presidente do sindicato dos metalúrgicos, setor no qual os acidentes aumentaram 44,4\% entre 2007 e 2008, complementou a explicação afirmando: "As empresas contrataram muito e não houve tempo para treinamento desses novos funcionários. Sem integração necessária, com aumento da demanda e ritmo de produção, excessos de hora extra e de jornada, o resultado foi o aumento de acidentes" (09/01/2009).

Em matéria publicada em 13 de abri de 2011, o técnico do serviço explicou a retomada do crescimento dos acidentes associada à retomada da economia em 2010: "nesse cenário, mais pessoas são contratadas, e a tendência é também aumentar a pressão por metas”. O crescimento também foi matéria relativa ao ano de 2011, embora tenha-se notado taxa menor, segundo o técnico do serviço (14/01/2012).

Em algumas dessas matérias, o jornal também descreveu ações de prevenção bem-sucedidas e duas intervenções conduzidas pelo Cerest em uma fábrica têxtil (07/03/2010) e em outra de móveis (13/04/2011). Em duas outras matérias, a temática foi ilustrada com casos dramáticos de acidentes: um eletricista teve um dedo perfurado por queda de objeto (09/01/2009) e um jovem trabalhador ficou tetraplégico, após sofrer queda quando duas portas pesando $80 \mathrm{~kg}$ caíram sobre ele (14/01/2012).

Em outros momentos, ao acompanhar as tendências dos casos de morte (oito mortes até o mês de outubro de 2012), uma queda fatal recente de carpinteiro em obra foi apresentada como ilustração pelo JP para mostrar a ação das instituiçóes públicas (Cerest, MTE) e do sindicato, bem como suas respectivas formas de explicar o acidente. A ausência de medidas de proteção coletiva e diversas irregularidades na obra explicaram a morte do trabalhador, contrariando o sócio-proprietário da empresa, que a considerou uma fatalidade e a justificou pela não utilização de cinto de segurança pelo trabalhador. 
O JP também dava voz aos técnicos do Cerest para expor o modo de ação empregado pelo serviço. Na notícia de 2007, o então coordenador do Cerest apresenta o funcionamento das açốes de vigilância, cuja base de informaçóes provinha do Sivat e a finalidade da ação preventiva era focada na proteção coletiva.

No caso das matérias envolvendo os acidentes do trabalho na construção civil, o JP acompanhou as ocorrências no município: 257 em 2005, 303 em 2006, 369 em 2007 e 1150 em 2012 (27/04/2013). Em 2013, o setor apresentava média de três acidentes por dia, sendo que ocupava o terceiro lugar entre setores da economia, após metalurgia e comércio atacadista (04/07/2013). Nesse acompanhamento do jornal, a presença do presidente do sindicato é uma constante, assim como os dados do Sivat. A participação de técnicos do serviço ocorreu em algumas das matérias; na matéria de 27/04/2013, o técnico do serviço afirmou ser importante, na análise de acidentes, deixar de atribuir as causas ao comportamento dos trabalhadores e buscá-las nos fatores organizacionais. $\mathrm{O}$ grande desafio seria a prevenção organizacional. No entanto, ao abordar os acidentes em grandes obras (04/07/2013), como a morte de cinco trabalhadores em acidente na obra de ponte vinculada ao anel viário da cidade três dias antes, o Cerest não foi citado (embora dados do Sivat tivessem sido utilizados).

Outras reportagens trataram de temas específicos: os atendimentos realizados pela Central de Ortopedia e Traumatologia do município (16/06/2007), a morosidade da justiça $(28 / 02 / 2010)$, os acidentes de trajeto (18/01/2012), acidentes no trabalho infantil (05/10/2013), trabalho doméstico (16/02/2014) e acidentes com máquinas $(12 / 10 / 2014)$.

O ponto de vista do jornal pode ser inferido a partir da leitura dos três editoriais publicados - "Acidentes de trabalho" (09/01/2009), "Prevenção de acidentes" e (28/04/2010) "Prevenção" (14/01/2012). Nota-se, por um lado, a preocupação com a questão dos acidentes de trabalho, daí o acompanhamento sistemático ao longo dos anos, e, portanto, a argumentação quanto à importância da prevenção e ao papel dos órgãos de fiscalização, como o Cerest. Por outro lado, observa-se visão reducionista do campo explicitada no primeiro editorial, quando se afirmou que conscientização e educação seriam as palavras de ordem, cabendo aos empresários cumprir a lei e fornecer equipamentos de proteção e, aos trabalhadores, estar atentos e utilizar os equipamentos $(09 / 01 / 2009)$.

\section{A cobertura das ações de vigilância ao longo do período}

O JP cobriu em 80 matérias nesses oito anos açôes de vigilância do serviço, incluindo audiências, encontros e acordos setoriais firmados e ou em curso, em diversos setores, tais como a produção de cana, olarias, supermercados, construção, entre outros.

A primeira ação setorial acompanhada pelo JP visava enfrentar as más condiçôes de trabalho no setor de corte de cana na região coberta pelo Cerest de Piracicaba, entre 2007 e 2009, em especial no combate às condiçôes precárias de moradia. Essa ação de caráter interinstitucional contou com a formação do Fórum da Cidadania e da Paz, no qual o Cerest participou, e com intervenção do MPT, que firmou acordo com as principais prefeituras envolvidas para favorecer a vigilância das moradias dos trabalhadores da cana (notícias de 22/02/2008 e 27/02/2008). O JP descreveu ação 
de força-tarefa composta pelo MPT, MTE e Cerest, que constatou irregularidades em cinco alojamentos (26/06/2008). Em 2009, ações de vigilância foram realizadas pelo Cerest logo no início da safra.

Entre 2008 e 2010, a cobertura foi feita envolvendo o setor de olarias na região, que se caracteriza pela existência de pequenas empresas que operam de modo muito precário e possuem péssimas condiçôes de trabalho e ambientais. Quatro matérias foram publicadas, cujos temas foram: compromisso firmado entre sindicato da construção e empresas para impedir contratação de menores de 18 anos (15/05/2008); audiência pública conduzida pelo MPT junto com empresas do setor para regularização das condiçôes de trabalho e de segurança após levantamento feito pelo Cerest, sindicato e MPT em 32 olarias (17/09/2008); retomada da operação de empresas do setor após paralisação devido à fiscalização ambiental pela Cetesb e intervenção do MPT (10/06/2010); e seminário no qual foi lançado o "Manual de prevenção de acidentes e doenças do trabalho nas olarias e cerâmicas vermelhas", redigido por técnico do Cerest (12/07/2010).

No ano de 2011, o JP dedicou três notícias sobre ação de vigilância nos supermercados da cidade, além de editorial sobre o tema.

A primeira notícia (09/02/2011) abordava demanda apresentada ao Cerest, pelo presidente do sindicato dos empregados no comércio, para fiscalização das condiçóes de trabalho nos supermercados. Para tratar dos problemas colocados, a coordenadora do serviço tornou público o modo de agir do serviço:

Num primeiro momento, faremos um trabalho de triagem com os maiores supermercados da cidade, levantando itens relacionados à saúde e à segurança do estabelecimento. A partir dessa amostragem, reuniremos os responsáveis dos demais supermercados para apresentarmos um balanço do que foi observado e dos procedimentos necessários. (Coordenadora do serviço)

Na segunda notícia (08/07/2011), a coordenadora apresentou o projeto para o diagnóstico, que contou com a parceria de diversas instituiçôes (MTE, sindicato, Associação Comercial de Piracicaba, Associação Paulista de Supermercados, entre outras), cujo objetivo era identificar causas dos acidentes e doenças do trabalho nos estabelecimentos. Empresas foram convidadas a participar do projeto, cujos resultados seriam apresentados em audiência pública, na qual o MTE iria notificar as empresas para corrigirem os problemas detectados e a se adequarem às normas vigentes, com prazos definidos em função da natureza dos problemas. Foi anunciado que a fiscalização da vigilância sanitária começaria no início de 2012.

A terceira matéria cobriu a audiência pública realizada na câmara dos vereadores para a apresentação do levantamento feito em 11 estabelecimentos, que contou com a presença de aproximadamente cinquenta empresários. No editorial de 18 de outubro, intitulado "Mercados em segurança”, o JP reconheceu a importância "de orientar os proprietários dos mercados [...] na prevenção de acidentes”, mas não apenas: "melhor ainda é ver estendida essa preocupação no que se refere a higiene e manuseio de alimentos”. 
O setor da construção foi o mais coberto ao longo do período, sendo que, dos 11 acidentes publicados, oito ocorreram no setor. Apenas um ocorreu em atividade não típica (a indústria cerâmica).

As açôes de vigilância no setor são contínuas, associadas ao funcionamento do Comitê Permanente Regional sobre Condiçốes e Meio Ambiente do Trabalho na Indústria da Construção (CPR), do qual o Cerest participava ativamente; e à importante parceria com o sindicato da construção. Em diversas notícias, a participação de técnicos do serviço decorreu após denúncia feita pelo sindicato. Notificações, embargos e interdições em obras e alojamentos de trabalhadores são os temas recorrentes, totalizando 33 matérias, além de matérias sobre ocorrências de acidentes (8) e matérias sobre audiências, encontros e atividades resultantes ou preparatórias das ações de fiscalização (8).

Pode ser observado pico de notícias sobre ações de vigilância no setor entre 2009 e 2012. Em 2009, oito notícias; em 2011, 25; e, em 2012, oito.

Em 2009, quatro matérias descreveram ações do serviço que levaram à interdição de obras do Poupatempo, sendo uma manchete (06/10/2017). Outra notícia com manchete constatou interdição de obra da sede dos bombeiros (30/07/2009).

O ano de 2011 foi um ano especial, com o início das obras para a implantação de montadora de automóveis no município, que contou com a instalação de diversas empresas e a chegada de muitos trabalhadores. Daí a ampla cobertura do jornal, que se estendeu a 2012, nas fiscalizações de alojamentos, açôes conjuntas envolvendo sindicato e o serviço e, posteriormente, intervenção do MPT nas construtoras responsáveis pela obra da planta da montadora. Ações também se voltaram a outras obras privadas, como banco e hipermercado, assim como a obras públicas municipais, como sede dos bombeiros e creche.

Algumas notícias sobre as fiscalizaçôes merecem destaque: a morte de um pedreiro em alojamento usado por construtora da planta da montadora, interditado pelo Cerest (15/09/2011); a interdição de caminhão-baú usado como alojamento de trabalhadores, que atuavam na construção de posto de gasolina (17/11/2011); e acidente fatal de jovem trabalhador na construção da planta da montadora (19/01/2012).

Diante dos 760 acidentes e três mortes ocorridas até setembro, foi realizada audiência pública na câmara, conduzida pelo Cerest, MTE e MPT, para conscientizar empregadores (cuja participação foi de $70 \%$ de 180 empresas convidadas), conforme matéria de 14/09/2011.

O jornal anunciou, em matéria, a realização de audiência pública em Campinas envolvendo MPT e as principais construtoras da planta da montadora (30/09/2011).

Por fim, uma notícia é publicada em 29/11/2011 sobre o endurecimento de regras impostas pela prefeitura para emitir licenças para empreiteiras, a fim de coibir alojamentos irregulares (o Cerest interditou 160 alojamentos nos 11 meses de 2011). Foi criada força-tarefa para tal, incluindo Secretaria de Obras; Trabalho e Renda; e Saúde.

Nesse ano de boom na construção civil, o jornal publicou artigo de opinião do presidente do sindicato dos trabalhadores no qual ressalta o esforço do sindicato para enfrentar as irregularidades nas obras, em especial, nos alojamentos de trabalhadores, cujo apoio do Cerest foi fundamental. 
Em 2012, mais três notícias tratam da interdição de alojamentos: as duas primeiras serviam para obras de posto de gasolina (31/01/2012 e 04/12/2012) e a terceira, para obras do programa Minha casa, minha vida (04/12/2012). A segunda notícia foi também manchete, uma vez que "trabalhadores moravam em caminhãobaú" (25/04/2012). Em 31/08/2012, foi noticiada a emissão de "notificação recomendatória à montadora asiática”, feita pelo MPT junto com o Cerest, visando adequar sua operação, que se iniciaria no mês seguinte, à legislação brasileira, no que tange às condições de segurança do trabalho. Tal notificação resultou do amplo esforço interinstitucional nas ações realizadas durante obra da planta (31/08/2012).

O jornal publicou matéria sobre ação conjunta, envolvendo MPT, MTE e Cerest, para a prevenção de acidentes em grande obra pública: o anel viário de Piracicaba. Seis obras foram interditadas, assim como duas torres de energia elétrica (26/09/2012).

A despeito dessas ações, o anel viário ainda foi objeto de notícias trágicas em 2013: na primeira, grave acidente foi objeto de reportagem pelo jornal, quando dois trabalhadores foram atingidos por uma peça que caiu após rompimento de cabo de sustentação (21/05/2013). Mas o pior aconteceu em julho, quando uma ponte em construção ruiu, causando a morte de cinco trabalhadores, citada em notícia de 04/07/2013.

Fiscalizaçôes isoladas também foram retratadas ao longo dos oito anos. Algumas merecem destaque, como a interdição de bancos no início de 2014, devido à falta de ar condicionado, e a fiscalização que flagrou "trabalhadores em situação similar à escravidão” em um canavial (09/09/2011). Essa última foi manchete de primeira página do jornal.

A cobertura do JP no caso dos acidentes de trabalho mostra tanto a dramaticidade e a violência quanto a banalização da vida no trabalho. De modo geral, as reportagens descrevem as circunstâncias do acidente, contando com as versôes dos diversos atores envolvidos na ocorrência - empresas - e na investigação - sindicato, Cerest, MTE e polícia civil.

Se em algumas delas (duas matérias com as datas de 01/07/2008 e 19/01/2012) as empresas envolvidas procuraram eximir-se da responsabilidade, transferindo a culpa para a vítima, a maioria das matérias apresenta a versão dos sindicalistas, responsabilizando as empresas e exigindo apuração dos fatos.

Assim, quando presentes e entrevistados, os técnicos do Cerest apresentavam análise preliminar das causas, assim como as medidas administrativas adotadas (infração, interdição, entre outras). No caso de grave acidente com mecânico em indústria cerâmica, o técnico do serviço disse: "elaboramos um auto de infração para que a empresa corrija eventuais irregularidades e instale proteçóes em todas as esteiras existentes em seu interior" (matéria de 28/06/2008).

Em algumas matérias (três), novas informações sobre acidentes já ocorridos e noticiados pelo jornal foram apresentadas. No caso do acidente referido acima (01/07/2008), no qual o mecânico teve seu braço amputado (28/06/2008), a empresa afirmou ter corrigido as proteçôes das partes móveis, conforme exigência do Cerest.

Observa-se, dessa forma, que o JP cobriu diversas ações de vigilância do serviço de importância local e regional, como alojamentos no setor da cana; péssimas condiçôes de operação e trabalho infantil nas olarias; alojamentos e acidentes na indústria de construção privada e pública; e até casos de trabalho escravo. 


\section{Discussão}

A análise da cobertura do jornal sobre a atuação do serviço e dos temas relacionados aos acidentes do trabalho reforça o papel do serviço para a prevenção de acidentes na região ${ }^{16} \mathrm{e}$ a importância da questão para o jornal, conforme apontam diversos editoriais analisados.

O que poderia explicar esse fato?

Em primeiro lugar, pode-se dizer que o tipo de mídia, impressa e regional ${ }^{2,6}$, favorece seu interesse pela questão, com impacto social e econômico locais, e pelos atores envolvidos (não apenas o Cerest).

Em segundo lugar, em Piracicaba, o enfrentamento aos acidentes é política pública reconhecida atrelada à forte ação interinstitucional. Assim, os sindicatos colocam a questão das condiçôes de trabalho na agenda política e as diferentes instituições são chamadas a se posicionar. Muitas matérias têm origem no trabalho de comunicação social de algumas entidades sindicais e instituiçóes ${ }^{15}$, destacando a presença dessas entidades e de seus parceiros (no caso, o Cerest), mas também nas questões das condições de trabalho.

Em terceiro lugar, ao implementar base de informaçôes precisas sobre os acidentes na regiáo, o Cerest favorece o acompanhamento das tendências e estatísticas, o que assegura embasamento técnico que favorece o enquadramento do tema pelo jornal. $\mathrm{O}$ Cerest passa a ser uma das "fontes oficiais" ${ }^{21}$ sobre a temática e suas informações são fonte de dados para as matérias.

A presença do Cerest e de seus técnicos no jornal garante espaço para sustentar a interpretação do serviço ${ }^{21} \mathrm{em}$ relação aos problemas de saúde e suas origens, cuja explicação, muitas vezes, exige olhar sistêmico e necessita compreender os fatores organizacionais. Do mesmo modo, sustentam a necessária proteção coletiva em detrimento da proteção individual preconizada pelas empresas. Além disso, a forma de atuação do serviço foi apresentada em diversas matérias, deixando transparente sua forma de ação.

O jornal, por sua vez, ao longo do período analisado, publicou diversas matérias sobre a problemática dos acidentes de trabalho, cobrindo várias açôes de vigilância e promoção realizadas pelo serviço e seus parceiros.

Alguns temas, como o trabalho doméstico, trabalho infantil e trabalho análogo ao trabalho escravo são objeto de publicação, reforçando a preocupação social com os contornos do trabalho na região. O Cerest teve presença recorrente, apresentando sua interpretação para a problemática dos acidentes.

Todavia, como mostrado em diversos estudos, alguns temas recebem maior destaque e/ou são mais salientes ${ }^{2,6}$. Observa-se, por exemplo, o uso de casos dramáticos de acidentes, que comovem, para ilustrar determinadas matérias. Da mesma maneira, as estatísticas e dados do Sivat são recorrentemente utilizados. No que tange aos setores da economia, embora não seja o setor com maior número de acidentes, a construção civil é o setor com maior número de notícias; em contrapartida, a metalurgia, com maior número de acidentes, teve número pequeno de notícias. Talvez a atuação de jornalistas a serviço da construção civil explique o fato ${ }^{15}$, associado ao crescimento do setor em 2011 devido à instalação da fábrica de montadora de automóveis na cidade.

No entanto, a atuação do Cerest na assistência e reabilitação não foi objeto de nenhuma matéria nesses oito anos, embora tais elementos sejam importantes para a 
preservação da saúde dos trabalhadores da região. Do mesmo modo, quando cobre os acidentes fatais, o jornal pouco se interessa pelas ações posteriores, na responsabilização das empresas e na construção de medidas de prevenção.

O enquadramento temático dos acidentes do trabalho dá voz aos diversos atores envolvidos ${ }^{2}$, sejam representantes do patronato, sejam atores do movimento sindical, sejam agentes do Estado. Apresenta também as controvérsias e interpretaçôes divergentes dos atores sociais, mas não defende ponto de vista próprio ou favorável a determinados atores, procurando se manter neutro ${ }^{3,21}$.

Todavia, ao referir a necessidade de conscientização dos trabalhadores, dessa forma responsabilizando-os pelos acidentes que sofrem, em editorial, o jornal parece se basear na visão tradicional do comportamento inseguro ${ }^{13}$. A tendência a reduzir o problema de natureza tão complexa no enquadramento do tema pode ser encontrada em outros jornais que cobrem questóes de saúde do trabalhador ${ }^{23}$.

Isso não reduz o papel fundamental do jornal, que sustenta a importância e qualidade da política pública conduzida pelo Cerest de Piracicaba nas narrativas que apresenta das ações do serviço. Confirma-se aqui o papel importante da mídia regional para resolução de problemas locais ${ }^{6}$.

\section{Limites do estudo}

A opção metodológica adotada foi realizar estudo descritivo, mas que cobriu todos os textos do período, para analisar a cobertura das ações de vigilância pelo jornal. As narrativas não foram exploradas em profundidade; o objetivo era verificar quais ações eram cobertas, qual papel e organização do serviço, alguns de seus resultados e produtos, conflitos, etc.

Optamos por analisar o enquadramento feito pelo JP, o principal jornal e de maior inserção histórica da região. Embora a literatura científica confirme vários aspectos da cobertura do jornal ${ }^{13,16,18}$, seus resultados não se estendem à mídia impressa local, uma vez que os outros jornais têm política editorial distinta ${ }^{14}$.

Quanto à temática dos acidentes, possivelmente há outras matérias publicadas no jornal que não referenciaram o serviço. Em novas pesquisas, a busca com outras palavras-chave, como acidente de trabalho ou prevenção, poderá ajudar a análise mais precisa sobre a participação do serviço, comparando-a com outros atores sociais.

\section{Comentários finais}

Açôes junto à mídia para melhorar a visibilidade dos serviços do SUS têm sido preconizadas ${ }^{13}$. No entanto, a mídia tende a se focar nas deficiências dos serviços públicos e, em muitos casos, difunde informaçóes pouco precisas sobre os problemas de saúde, associando-os aos comportamentos das pessoas ${ }^{7,8}$.

Os resultados desta pesquisa mostram o contrário, ou seja, mostram que o JP incorporou a temática dos acidentes de trabalho na região e, dessa forma, ao acompanhar as açôes do Cerest, difunde imagem respeitosa de sua atuação e de sua visão, mais ampla sobre os acidentes do trabalho e sobre suas origens organizacionais. 


\section{Contribuições dos autores}

Todos os autores participaram da elaboração e desenvolvimento da pesquisa; da análise e discussão dos resultados; e da redação e revisão do texto, cuja versão final foi aprovada por todos.

\section{Agradecimentos}

À Fundação de Amparo à Pesquisa de São Paulo, pelo financiamento do projeto temático “Acidente de trabalho: da análise sociotécnica à construção social de mudanças", processo 2012/04721-1.

Ao professor Rodolfo Andrade de Gouveia Vilela, coordenador do projeto temático, pelo suporte e inspiração ao longo desta pesquisa.

Aos profissionais do Cerest de Piracicaba, por seu engajamento no campo da Saúde do Trabalhador e pela cooperação ao longo dos últimos 15 anos.

\section{Direitos autorais}

Este artigo está licenciado sob a Licença Internacional Creative Commons 4.0, tipo BY (https://creativecommons.org/licenses/by/4.0/deed.pt_BR).

$(\mathrm{cc})$ (

\section{Referências}

1. Penteado CC, Fortunato I. Mídia e políticas públicas: possíveis campos exploratórios. Rev Bras Cienc Soc. 2015; 30(87):129-41.

2. Silva G. Para pensar critérios de noticiabilidade. Est J Midia. 2005; 2(1):95-107.

3. Miguel L. Os meios de comunicação e a prática da política. Lua Nova. 2002; (5556):155-84.

4. Biroli F, Miguel LF. Orgulho e preconceito: a "objetividade" como mediadora entre o jornalismo e seu público. Opin Publica. 2012; 18(1):22-43.

5. Rocha RL. Os negócios da mídia e a comunicação da saúde. Cad Saude Publica. 2016; 32(2):1-3.

6. Crow DA. Local media and experts: sources of environmental policy initiation. Policy Stud J. 2010; 38(1):143-64.

7. Oliveira VC. A comunicação midiática e o Sistema Único de Saúde. Interface (Botucatu). 2000; 4(7):71-80.

8. Araújo IS. Um olhar sobre as relações entre o SUS e a mídia. In: Seminário SUS 20 anos: desafios para a informação e comunicação em saúde; 2009; Rio de Janeiro. Rio de Janeiro: Fundação Oswaldo Cruz; 2009. p. 62-9.

9. Rios C, Ortega F, Zorzanelli R, Nascimento LF. Da invisibilidade à epidemia: a construção narrativa do autismo na mídia impressa brasileira. Interface (Botucatu). 2015; 19(53):325-36.

10. Vaz P. Mídia, moralidade e fatores de risco em saúde. Cad Saude Publica. 2009; 25(3):472-3. 
11. Soares GB, Caponi S. Depressão em pauta: um estudo sobre o discurso da mídia no processo de medicalização da vida. Interface (Botucatu). 2011; 15(37):437-46.

12. Hale A. Introduction: the goals of event analysis. In: Hale A, Wilpert B, Freitag M, organizadores. After the event, from accident to organisational learning. Oxford: Pergamom; 1997. p. 1-10.

13. Vilela RAG, Almeida IM, Mendes RWB. Da vigilância para prevenção de acidentes de trabalho: contribuição da ergonomia da atividade. Cienc Saude Colet. 2012; 17(10):2817-30.

14. Carvalho PB, Decloedt AL, Golim PO, Gomes ALZ, Rocha VMS. Do que temos ao que queremos: apontamentos da pesquisa com gestores e instâncias do controle social sobre a questão da comunicação nos centros de referência em saúde do trabalhador do estado de São Paulo. Anagrama [Internet]. 2008 [citado 11 Mar 2017]; 2(4):1-11. Disponível em: https://www.revistas.usp.br/anagrama/article/view/35332/38052

15. David HG. Saúde do trabalhador na manchete do jornal: análise descritiva do caso do Centro de Referência em Saúde do Trabalhador (CEREST) de Piracicaba - SP [dissertação]. São Paulo: FUNDACENTRO; 2014.

16. Jackson Filho JM, Barreira THC. A construção da saúde do trabalhador em Piracicaba: análise da ação pública no período de 1998 a 2009. In: Simonelli AP, Rodrigues DS, organizadores. Saúde do trabalho em debate: velhas questôes, novas perspectivas. Brasília: Paralelo 15; 2013. p. 357-92.

17. Brasil. Ministério da Saúde. Instrução normativa sobre ações de vigilância em saúde do trabalhador no SUS. Portaria no 3.120, de 1 de Julho de 1998. Diário Oficial da República Federativa do Brasil. 2 Jul 1990.

18. Vilela RAG, Jackson Filho JM, Querol MAP, Gemma SFB, Takahashi MAC, Gomes MHP, et al . A expansão do objeto da vigilância em acidente do trabalho: história e desafios de um centro de referência em busca da prevenção. Cienc Saude Colet. 2018; 23(9):3055-66.

19. Queiroz ACF, Oliveira D. Jornais centenários de São Paulo. Piracicaba: Degaspari; 2002.

20. Instituto Brasileiro de Geografia e Estatística. Panorama: cidade de Piracicaba. São Paulo: IBGE; 2018 [citado 21 Nov 2018]. Disponível em: https://cidades.ibge.gov.br/ brasil/sp/piracicaba/panorama

21. Porto M. Enquadramentos da mídia e política. In: Rubim AAC, organizador. Comunicação e política: conceitos e abordagens. Salvador, São Paulo: Edufba, Unesp; 2004. p. 73-104.

22. Mendonça RF, Simões P. Enquadramento: diferentes operacionalizações analíticas de um conceito. Rev Bras Cienc Soc. 2012; 27(79):117-235.

23. Rangel MS. Imagens e sentidos no discurso da mídia impressa acerca de uma epidemia de intoxicação ocupacional por benzeno. Interface (Botucatu). 2006; 9(18):77-92. 
The prevention of occupational accidents is not an issue frequently covered by the print media. The aim of this study was to identify and describe the issues and actions promoted by Piracicaba Occupational Health Reference Center (Cerest), in Piracicaba, Sao Paulo State, Brazil, that attracted the interest of the local newspaper Jornal de Piracicaba and the image the newspaper promotes of the service and the issue of occupational accidents. A total of 146 texts published between 2007 and 2014 were analyzed in two categories: occupational accidents and occupational health surveillance. The findings show that the newspaper gives a voice to the actors involved and bases its coverage on the information and actions developed by the service, thus legitimizing occupational safety and health policy and the role of the local media in resolving social problems involving the community.

Keywords: Journalism. Occupational health. Public policy. Surveillance. Occupational accidents.

La prevención de accidentes de trabajo no es un tema frecuente en los medios impresos. La actuación del Centro de Referencia en Salud del Trabajador de Piracicaba, estado de Sao Paulo, Brasil (Cerest) pone esa problemática en el centro del debate social en la región. El objetivo de esa investigación fue identificar y describir los temas y acciones del Centro que suscitaron el interés del Jornal de Piracicaba, el principal del municipio y la visión que propaga sobre el servicio y sobre el tema. Se analizaron, bajo dos categorías, 146 textos publicados entre 2007 y 2014: problemática de los accidentes de trabajo y acciones de vigilancia. Se verificó que el periódico da voz a los actores sociales envueltos. Fundamenta su cobertura con informaciones y acciones desarrolladas por el servicio. Colabora, por lo tanto, en la legitimización de la política pública conducida por el Centro y del papel de los medios locales para la resolución de problemas sociales que envuelven a la comunidad.

Palabras clave: Periodismo. Salud del trabajador. Política pública. Vigilancia. Accidente de trabajo. 